\title{
Robot-assisted stereotactic brain biopsy: systematic review and bibliometric analysis
}

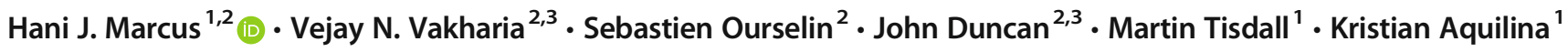

Received: 26 March 2018 / Accepted: 2 May 2018 / Published online: 10 May 2018

(C) The Author(s) 2018

\begin{abstract}
Introduction Stereotactic brain biopsy represents one of the earliest applications of surgical robotics. The aim of the present systematic review and bibliometric analysis was to evaluate the literature supporting robot-assisted brain biopsy and the extent to which the scientific community has accepted the technique.

Methods The Cochrane and PubMed databases were searched over a 30-year period between 1st of January 1988 and 31st of December 2017. Titles and abstracts were screened to identify publications that met the following criteria: (1) featured patients with brain pathology, (2) undergoing stereotactic brain biopsy, (3) reporting robot-assisted surgery, and (4) outcome data were provided. The reference lists of selected studies were also sought, and expert opinion sought to identify further eligible publications. Selected manuscripts were then reviewed, and data extracted on effectiveness and safety. The status of scientific community acceptance was determined using a progressive scholarly acceptance analysis.

Results All identified studies were non-randomised, including 1 retrospective cohort study and 14 case series or reports. The diagnostic biopsy rate varied from 75 to $100 \%$, and the average target accuracy varied from 0.9 to $4.5 \mathrm{~mm}$. Use of the robot was aborted in two operations owing to geometric inaccessibility and an error in image registration but no associated adverse events were reported. A compounding progressive scholarly acceptance analysis suggested a trend towards acceptance of the technique by the scientific community.

Conclusions In conclusion, robot-assisted stereotactic brain biopsy is an increasingly mainstream tool in the neurosurgical armamentarium. Further evaluation should proceed along the IDEAL framework with research databases and comparative trials.
\end{abstract}

Keywords Surgery $\cdot$ Robotics $\cdot$ Stereotaxy $\cdot$ Diffuse intrinsic brainstem glioma $\cdot$ DIPG

\section{Introduction}

Surgical robotics is amongst the most important technologies to emerge over the last decade [1]. Surgical robots may result in higher accuracy and precision than would otherwise be possible. The clinical corollary is that such

Hani J. Marcus and Vejay N. Vakharia contributed equally to this work.

Hani J. Marcus

h.marcus@ucl.ac.uk

1 Department of Neurosurgery, Great Ormond Street Hospital, London, UK

2 Wellcome EPSRC Centre for Interventional and Surgical Sciences, University College London, 8.02 Malet Place Building, Gower Street, London WC1E 6BT, UK

3 UCL Institute of Neurology, National Hospital for Neurology and Neurosurgery, Queen Square, London WC1N 3BG, UK robots may ultimately improve the safety and effectiveness of surgical interventions.

Stereotactic brain biopsy represents one of the earliest applications of surgical robotics. On the 11th of April 1985, a team at the Memorial Medical Center used a modified PUMA industrial robot (Advance Research \& Robotics, CT, USA) to perform a robot-assisted stereotactic brain biopsy in a 52-yearold man [2]. Since this initial report, many surgical robots have been used to perform stereotactic brain biopsy including the Neuromate (Renishaw, Gloucestershire, UK), ROSA (Medtech, Montpellier, France), and Renaissance (Mazor Robotics, Caesarea, Israel) robots. Anecdotally, robotassisted stereotactic brain biopsy has been adopted within the neurosurgical community.

Over recent years, considerable emphasis has been placed on the methodology of translation of new devices such as surgical robots from the laboratory to the operating room, the central tenet being that innovation and evaluation can, and should, proceed together in an ordered and logical manner [3-5]. The aim of the present systematic review and 
bibliometric analysis was to evaluate the literature supporting robot-assisted brain biopsy and the extent to which the scientific community has accepted the technique.

\section{Methods}

The study protocol was registered on the international prospective register of systematic reviews (PROSPERO CRD42017082204). The Preferred Reporting Items for Systematic Reviews and Meta-Analyses (PRISMA) Statement was used in the preparation of this manuscript [6].

\section{Search methods}

Two authors (HJM and VNV) independently searched the Cochrane Central Register of Controlled Trials (CENTRAL) and PubMed databases over a 30-year period between 1st of January 1988 (the year of the first publication) and 31st of December 2017. Search terms were generated with the PICO tool (Problem, Intervention, Comparison, and Outcome) and the Boolean free-text search [(brain OR brainstem OR cerebral OR cerebellar) AND (biopsy OR biopsies) AND (robot OR robotic)] used. The last date of the search was undertaken on the 4th of January 2018. The reference lists of selected studies were also sought, and expert opinion sought to identify further eligible publications. Duplicates were then removed and an English language restriction applied.

\section{Eligibility criteria}

Titles and abstracts were screened to identify publications that met the following criteria: (1) featured patients with brain pathology, (2) undergoing stereotactic brain biopsy, (3) reporting robot-assisted surgery, and (4) outcome data were provided. Full publications were then obtained and assessed for eligibility. Any discrepancies were resolved by consensus and discussion with the senior author.

\section{Data extraction}

The following data were extracted from eligible full publications: (1) study settings including institution and country of origin, (2) study design, (3) study group characteristics, (3) surgical robot details, (4) effectiveness outcomes including biopsy yield and accuracy, and (5) safety outcomes including haemorrhage, transient or permanent worsening neurological deficits, and mortality. Corresponding authors were contacted to provide supplemental data when required.

\section{Appraisal of evidence}

The Methodological Index for Non-Randomised Studies (MINORS) and Jadad scoring systems were undertaken by two researchers independently (VNV and HJM) and used to appraise non-randomised and randomised studies respectively $[7,8]$. Correlation between the scores attributed to the studies was calculated using Cronbach's $\alpha$. Studies of higher quality were given greater weighting in the qualitative review. A pooled analysis of the diagnostic biopsy rate was undertaken with weightings determined by the number of patients in each study. Statistical analysis was performed using SPSS v 24.0 (IBM, IL, USA) and Stata v14 (Statacorp, TX, USA).

\section{Progressive scholarly acceptance}

A bibliometric analysis was performed to determine the extent to which the scientific community has accepted robot-assisted stereotactic brain biopsy. All studies were coded as either an initial investigation or refining study according to the criteria outlined by Schnurman et al. [9, 10]. A compounding model was then used to determine the progressive scholarly acceptance end-point whereby the number of refining studies surpasses the number of initial investigations, implying that the scientific community has accepted the initial questions of effectiveness and safety; some innovations rapidly achieve this transition whilst others fail to ever do so.

\section{Results}

\section{Summary of search strategy, types of study, and quality of evidence}

The database search returned 249 results of which 242 were English language. Screening titles and abstracts identified 24 publications for full manuscript review (Fig. 1). A comparison of the articles identified between the two independent researchers revealed high concordance between included studies. In all, 15 studies were included in the systematic review, comprising a total of 322 patients that underwent 328 robotassisted brain biopsies (Table 1). As only four studies provided accuracy data and there was no consistent reporting, we were unable to perform a meta-analysis.

All included studies were non-randomised in design including 1 retrospective cohort study and 14 case series or reports (level 4 evidence) [11]. The MINORS system was used to evaluate the quality of these studies, with a high concordance of calculated scores $(\alpha=0.98)$. Studies were of variable quality but few were prospective and none prospectively performed a power calculation for sample size (Table 2).

Dellaretti et al. reported a retrospective cohort comparing transcortical and transcerebellar approaches in 142 patients 
Fig. 1 PRISMA flow diagram outlining the study selection process. From: Moher D, Llberati A, Tetzlatf J, Altman DG, The PRISMA Group (2009).

Preferred Reporting items for Systematic Reviews and MetaAnalyses: The PRISMA Statement. Plos Med 6(7): e1000097. https://doi.org/10. 1371/journal.pmed1000097. For more information, visit http:// www.prisma-statement.org
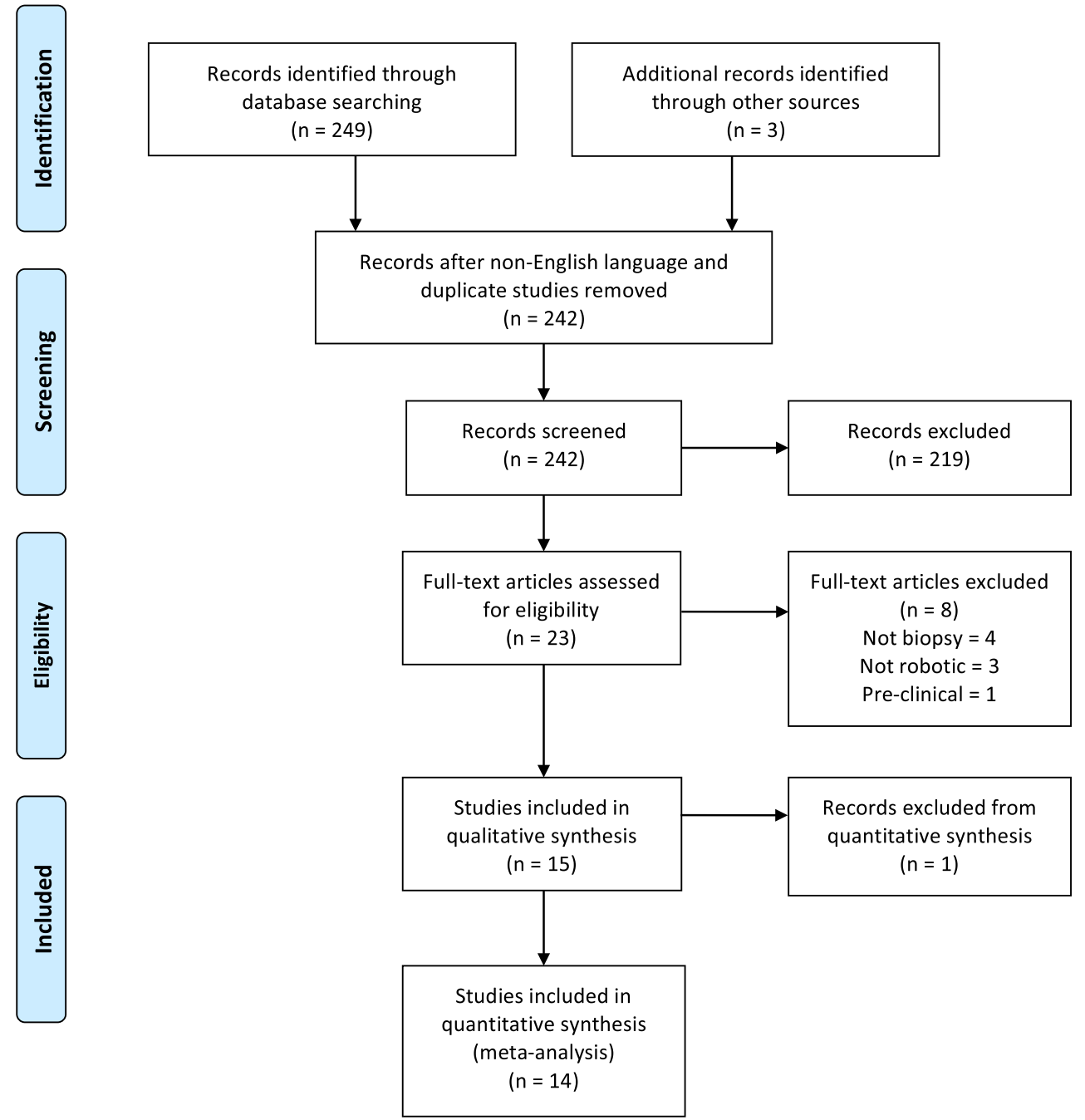

that underwent brain biopsy, of which 33 patients underwent a robot-assisted brain biopsy [12]. Unfortunately, the clinical outcomes of this subset of patients were not separately reported and they have therefore not been included in the pooled analysis of effectiveness and safety.

\section{Surgical robots}

Six studies reported use of the ROSA robot [13-18] and two the Neuromate robot $[12,19]$; the other robots used were the Puma 200 robot [2], Renaissance robot [20], Minerva robot (Swiss Federal Institute of Technology of Lausanne, Switzerland) [21], MKM robot (Zeiss, Oberkochen, Germany) [22], Surgiscope robot (ISIS, Grenoble, France) [23], iSYS1 robot (iSYS, Kitzbühel, Austria) [24], and RONNA G3 robot (University of Zagreb, Croatia) [25]. The size and configuration of the reported devices varied significantly with the ROSA and Neuromate robots, occupying a large footprint and weighing up to $200 \mathrm{~kg}$, and the Renaissance and iSYS1 robots being small enough to fix directly to the patient's head and Mayfield clamp respectively, and weighing as little as $1.4 \mathrm{~kg}[20,24]$.

All robots had a supervisory-controlled function in which the surgeon planned a safe surgical trajectory using preoperative volumetric imaging, image registration was performed using frame-based or frameless methods, and the robot supervision of the surgeon [26]. This trajectory was then used by the surgeon to perform the incision, burr hole craniostomy, and biopsy.

\section{Effectiveness}

The diagnostic biopsy rate varied from 75 to $100 \%$ in individual series. Weighted averages based on the number of patients in each study revealed a pooled diagnostic biopsy rate of 94.9\% (280/295).

Accuracy measures were provided in six studies, and quantitative data provided in four studies. Within these studies, accuracy measures varied and included Euclidean distance then carried out trajectory alignment autonomously under the 


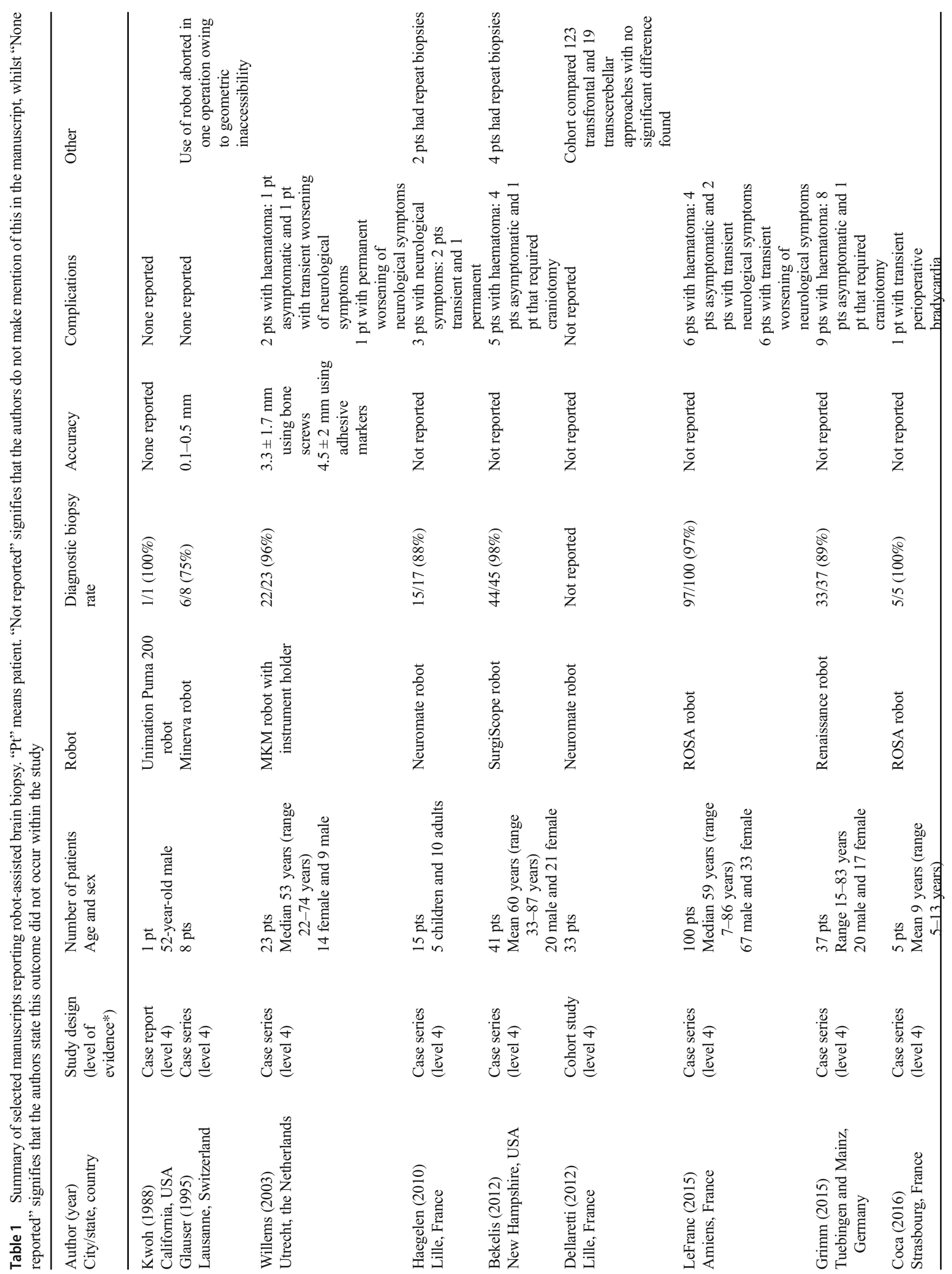




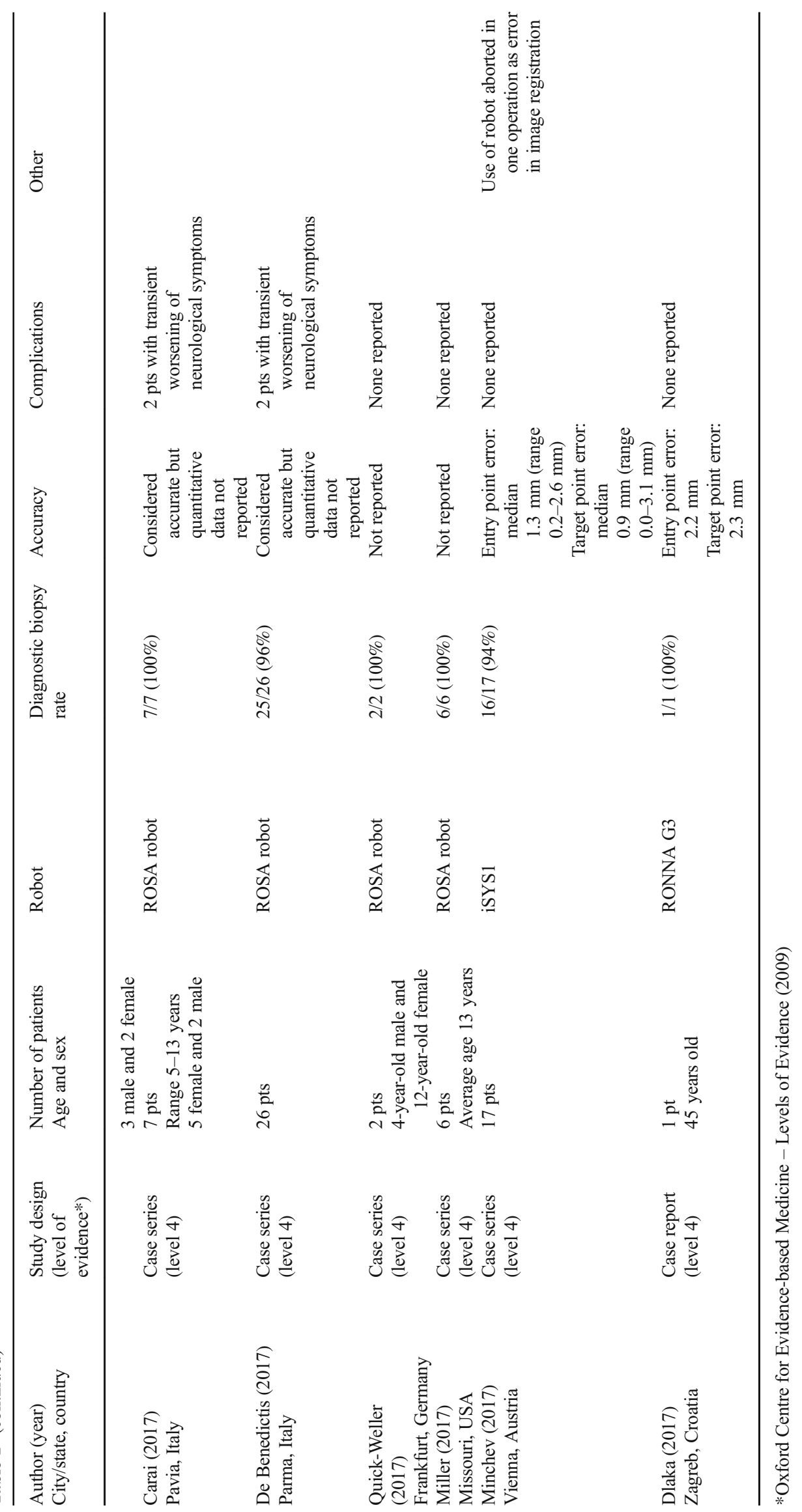




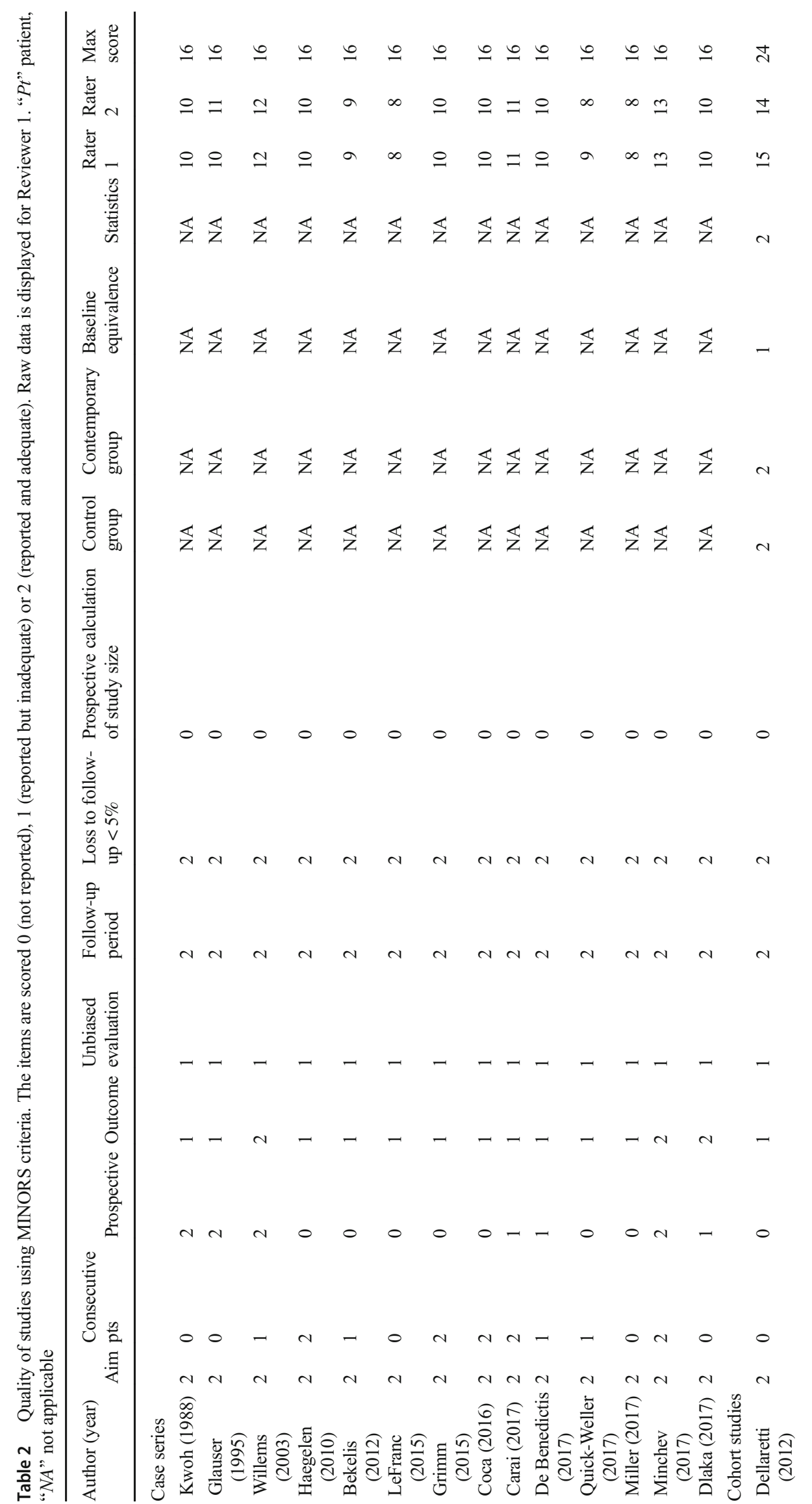


and lateral deviation, or were not specified. When reported, the average target accuracy varied from 0.9 to $4.5 \mathrm{~mm}$.

In the majority of studies, the registration method was not specified. Willems et al. compared the target accuracy of the MKM robot using different registration methods and found that bone-anchored fiducials resulted in significantly greater accuracy than adhesive scalp markers $(3.3 \pm 1.7$ versus $4.5 \pm 2 \mathrm{~mm})$ [22].

Only two studies provided accuracy measures for the entry and target point separately. Minchev et al. reporting on use of the iSYS1 robot in 25 patients calculated a median entry point accuracy of $1.3 \mathrm{~mm}$ (range $0.2-2.6 \mathrm{~mm}$ ) and a median target point accuracy of $0.9 \mathrm{~mm}$ (range $0.0-3.1 \mathrm{~mm}$ ) [24]. Dlaka et al. reporting on the RONNA G3 robot in a single patient calculated an entry point error of $2.2 \mathrm{~mm}$ and target point error of $2.3 \mathrm{~mm}[25]$.

\section{Safety}

Use of the robot was aborted in two operations owing to geometric inaccessibility and an error in image registration but no associated adverse events were reported.

Safety measures reported included haemorrhage rate, transient or permanent worsening neurological deficits, and mortality rate. Post-operative haematoma was reported in $7.5 \%$ $(22 / 295)$ but it is unclear how many patients underwent a routine post-operative scan and only $0.7 \%$ (2/295) developed a symptomatic haemorrhage that required craniotomy and evacuation of the haematoma. Neurological deficits occurred in $5.1 \%(15 / 295)$ and permanent neurological deficits in $0.7 \%$ $(2 / 295)$. No mortalities were reported in the pooled analysis.

\section{Progressive scholarly acceptance}

There was a trend towards an increasing number of publications per annum and an increasing volume of procedures per annum (Fig. 2a, b). A compounding progressive scholarly acceptance analysis suggested an early convergence pattern (Fig. 2c), indicating a trend towards acceptance of the technique by the scientific community.

\section{Discussion}

\section{Summary of evidence}

Since the first published report 30 years ago, over 300 patients have undergone robot-assisted brain biopsy. In our pooled analysis, surgery was effective with $95 \%$ of procedures resulting in a diagnosis. Although use of the robot had to be aborted in two procedures due to technical errors, there were no associated adverse events as a result of this, and less than $1 \%$ of patients had a significant post-operative haematoma or permanent neurological deficit. These findings are further supported by our bibliometric analysis using the progressive scholarly acceptance model, which suggests that the scientific community has begun to accept robot-assisted brain biopsy.

Early surgical robots were modified industrial robots and were large, complex, and expensive. A recent trend towards smaller, simpler, and less expensive platforms has corresponded to their increased adoption within neurosurgery, and the number of procedures that utilises them has grown [27]. These include conventional stereotactic procedures that mandate high accuracy and precision, and have previously relied on frame-based techniques, such as deep brain stimulation [28], stereoelectroencephalography (SEEG) [20], and intracranial catheter placement [24].

Historically, many surgical device innovations have been adopted with little or no evidence to support their effectiveness and safety. In the USA, the majority of such devices are cleared through the $510(\mathrm{k})$ pathway, which does not require clinical studies [29]. The introduction of devices following clearance is unstructured and variable; more often than not, their use is reported in non-comparative trials without institutional board review. This process carries an obvious risk to patient safety, and a number concerns have been raised regarding the lack of centralised adverse event reporting [30]. To address this shortfall, the Balliol Collaboration has proposed the IDEAL model for safe innovation [3-5]. To this end, our bibliographic analysis suggests that robot-assisted brain biopsy currently lies in Phase $2 b$ (Exploration) and that research databases and comparative trials are now warranted (Table 3 ).

\section{Comparison with other studies}

To our knowledge, there have been no previous reviews evaluating the accuracy, effectiveness, and safety of robot-assisted brain biopsy. However, our pooled analyses of outcome data are comparable with previously reported non-robotic framebased and frameless biopsy series [31].

Khatab et al. reviewed 16 studies in which 1628 frameless brain biopsies were performed using optical guidance, and found an average diagnostic yield of 93.8\% [32]. Similarly, Frati et al. reported on 296 cases over an 8-year period from a single institution that underwent frameless biopsy with a diagnostic yield of 99.7\% [33]. Harrisson et al. reported pinless frameless biopsy in 149 patients with electromagnetic guidance and found that 5 cases were non diagnostic, although in 4 of these cases, the specimen was of abnormal tissue but the pathologist was unable to make a diagnosis [34]. This highlights an important limitation in using diagnostic biopsy rate as an outcome measure as newer genetic markers may improve the diagnostic rates in the future. 
Fig. 2 Graphs demonstrating a the number of overall publications per annum, $\mathbf{b}$ the number of patients reported undergoing robot-assisted biopsy per annum, and $\mathbf{c}$ the number of initial and refining publications per annum
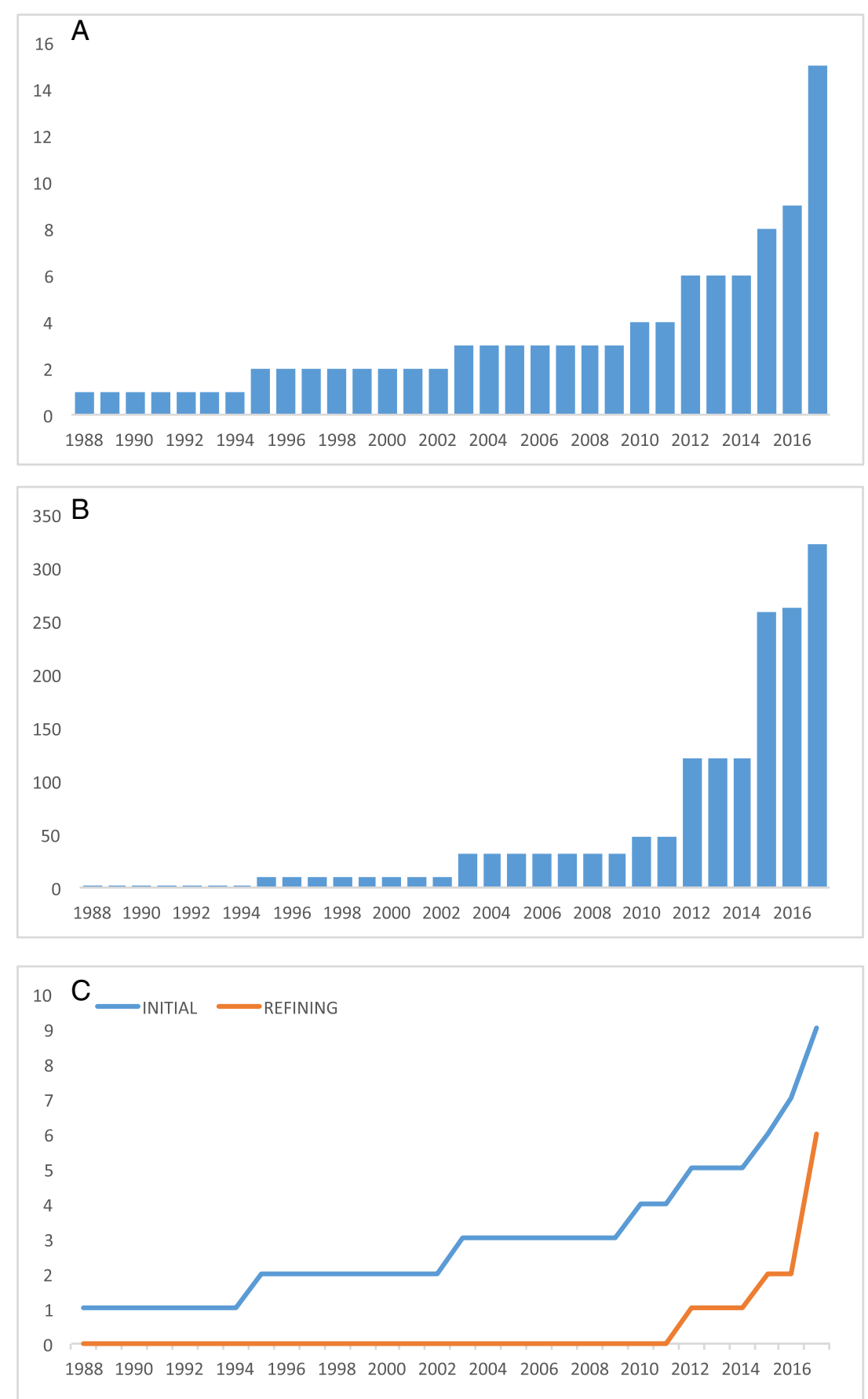

Few studies have reported the accuracy of brain biopsy. In a single-centre randomised controlled trial, Bradac et al. compared frame-based and frameless brain biopsy in 53 patients and calculated a target point accuracy of $2.65 \pm 1.12$ and 2.90 $\pm 1.26 \mathrm{~mm}$ respectively [35].

Kulkarni et al. investigated the rate of haemorrhages following non-robotic stereotactic biopsy in 102 patients based on post-operative CT scans [36]. This revealed 59.8\% (61/ 102) patients developed haemorrhages of which $54.9 \%$ (56/
102) were intracerebral. The incidence of clinically significant symptomatic haemorrhage was $5.8 \%$ (6/102) whilst the remaining $53.9 \%(55 / 102)$ were clinically silent. This raises the question of whether clinically silent haemorrhages are a useful outcome measure as they ultimately have no effect on the patient. Further, it is likely that had patients undergone post-biopsy MRI sequences that are more sensitive to blood products, such as susceptibility-weighted imaging, an even greater incidence would have been detected. 
Table 3 Defining characteristics of phases of surgical and interventional innovations (adapted from http://www.ideal-collaboration.net/about-ideal/ ideal-summary-tables/)

\begin{tabular}{|c|c|c|c|c|c|}
\hline & 1. Idea & 2a. Development & 2b. Exploration & 3. Assessment & $\begin{array}{l}\text { 4. Long-term } \\
\text { monitoring }\end{array}$ \\
\hline Purpose & Proof of concept & Development & Learning & Assessment & Surveillance \\
\hline $\begin{array}{l}\text { Number and types } \\
\text { of patients }\end{array}$ & $\begin{array}{l}\text { Single digit; } \\
\text { highly selected }\end{array}$ & Few; selected & Many; may expand indications & $\begin{array}{l}\text { Many; expanded } \\
\text { indications }\end{array}$ & All eligible \\
\hline $\begin{array}{l}\text { Number and types } \\
\text { of surgeons }\end{array}$ & Very few & $\begin{array}{l}\text { Few; innovators and some } \\
\text { early adopters }\end{array}$ & $\begin{array}{l}\text { Many; innovators, early } \\
\text { adopters, early majority }\end{array}$ & Many; early majority & All eligible \\
\hline Study types & $\begin{array}{l}\text { Structured case } \\
\text { reports }\end{array}$ & $\begin{array}{l}\text { Prospective development } \\
\text { studies }\end{array}$ & $\begin{array}{l}\text { Research databases; feasibility } \\
\text { RCT }\end{array}$ & $\begin{array}{l}\text { Surgical randomised } \\
\text { controlled studies }\end{array}$ & $\begin{array}{r}\text { Prospective } \\
\text { registries }\end{array}$ \\
\hline
\end{tabular}

\section{Limitations}

The present review was restricted to relatively few studies, of variable size and quality, and with inconsistent reporting of surgical outcomes, which necessarily limits the conclusions that can be drawn. This finding is consistent with an innovation in the early adoption phase [37].

In practice, the accuracy and precision of surgical robots depends on a number of factors. Arguably, the most important of these is the registration of the patient to the pre-operative reference imaging, upon which the biopsy trajectory has been planned. Image registration can be in the form of fiducial markers, with Willems et al.'s finding that bone-anchored fiducials resulted in significantly greater accuracy than adhesive scalp markers [22]. The use of intra-operative imaging allows automatic registration methods with greater accuracy than scalp and bone-anchored fiducials [38].

Other factors that may influence surgical outcome of robotassisted brain biopsy include the location of the lesion, the planned trajectory, and the histological nature of the lesion. Dellaretti et al. compared transcortical and transcerebellar approaches in patients undergoing brainstem biopsy and did not find any significant difference in outcomes [12]. Nonetheless, given that there is no systematic or objective means of trajectory planning at present, this remains a significant confounding factor.

Careful trajectory planning is critical to avoiding complications in stereotactic procedures. In stereotactic brain biopsy procedures that utilise a burr hole craniostomy for trajectory determination, it is not possible to visualise the cortical vasculature. The safety of such procedures is therefore dependent on the ability of pre-operative imaging to visualise cerebral vasculature so that planned trajectories avoid this along their entire length. Avoiding sulcal-pial boundaries, reducing intracerebral length, and orthogonal traversing of the skull have all been suggested to improve safety of stereotactic procedures [39]. Computer-assisted algorithms for trajectory planning have been shown to optimise these factors in a systematic fashion for DBS and SEEG, but there are no studies that have utilised this for stereotactic biopsy planning [39, 40].

\section{Conclusions}

Robot-assisted stereotactic brain biopsy is an increasingly mainstream tool in the neurosurgical armamentarium. Although limited, the literature suggests the technique is as effective and safe as the existing frame-based and frameless biopsy. Moreover, our bibliometric analysis suggests that the scientific community has begun to accept robot-assisted brain biopsy. Further evaluation should proceed along the IDEAL framework with research databases and comparative trials.

Author contributions HJM and VV were involved in the acquisition of data, analysis of data, and drafting the manuscript. MT and KA were involved in the study conception and critical revision of the manuscript. SO and JD carried out critical revision of the manuscript.

\section{Compliance with ethical standards}

Conflict of interest All authors have completed the ICMJE uniform disclosure form at www.icmje.org/coi_disclosure.pdf and declare no financial relationships with any organisations that might have an interest in the submitted work in the previous three years, and no other relationships or activities that could appear to have influenced the submitted work.

Ethical approval Ethical approval was not sought as this was a review study.

Informed consent Informed consent was not sought, as this was a review study.

Copyright The corresponding author has the right to grant on behalf of all authors and does grant on behalf of all authors a worldwide licence to the publishers and its licensees in perpetuity, in all forms, formats and media (whether known now or created in the future), to (i) publish, reproduce, distribute, display, and store the contribution; (ii) translate the contribution into other languages, create adaptations and reprints, include within collections, and create summaries, extracts, and/or abstracts of the contribution; (iii) create any other derivative work(s) based on the contribution; (iv) exploit all subsidiary rights in the contribution; (v) include electronic links from the contribution to third-party material wherever it may be located; and (vi) license any third party to do any or all of the above. 
Open Access This article is distributed under the terms of the Creative Commons Attribution 4.0 International License (http:// creativecommons.org/licenses/by/4.0/), which permits unrestricted use, distribution, and reproduction in any medium, provided you give appropriate credit to the original author(s) and the source, provide a link to the Creative Commons license, and indicate if changes were made.

\section{References}

1. Hughes-Hallett A, Mayer EK, Marcus HJ, Cundy TP, Pratt PJ, Parston G, Vale JA, Darzi AW (2014) Quantifying innovation in surgery. Ann Surg 260:205-211. https://doi.org/10.1097/SLA. 0000000000000662

2. Kwoh YS, Hou J, Jonckheere EA, Hayati S (1988) A robot with improved absolute positioning accuracy for $\mathrm{CT}$ guided stereotactic brain surgery. IEEE Trans Biomed Eng 35:153-160. https://doi.org/ $10.1109 / 10.1354$

3. Cook JA, McCulloch P, Blazeby JM, Beard DJ, Marinac-Dabic D, Sedrakyan A (2013) IDEAL framework for surgical innovation 3: randomised controlled trials in the assessment stage and evaluations in the long term study stage. BMJ 346:f2820

4. Ergina PL, Barkun JS, McCulloch P, Cook JA, Altman DG (2013) IDEAL framework for surgical innovation 2: observational studies in the exploration and assessment stages. BMJ 346:f3011

5. McCulloch P, Cook JA, Altman DG, Heneghan CDM (2013) IDEAL group. IDEAL framework for surgical innovation 1: the idea and development stages. BMJ 346:f3012

6. Liberati A, Altman DG, Tetzlaff J, Mulrow C, Gøtzsche PC, Ioannidis JPA, Clarke M, Devereaux PJ, Kleijnen J, Moher D (2009) The PRISMA statement for reporting systematic reviews and meta-analyses of studies that evaluate health care interventions: explanation and elaboration. J Clin Epidemiol 62:e1-e34. https:// doi.org/10.1016/j.jclinepi.2009.06.006

7. Jadad AR, Moore RA, Carroll D, Jenkinson C, Reynolds DJM, Gavaghan DJ, Dm HJM, Regional O, Relief P (1996) Assessing the quality of reports of randomized clinical trials: is blinding necessary? 12:1-12

8. Slim K, Nini E, Forestier D, Kwiatkowski F, Panis Y, Chipponi J (2003) Methodological index for non-randomized studies (MINORS): development and validation of a new instrument. ANZ J Surg 73:712-716. https://doi.org/10.1046/j.1445-2197. 2003.02748.x

9. Schnurman Z, Kondziolka D (2016) Evaluating innovation. Part 1: the concept of progressive scholarly acceptance. J Neurosurg 124: 207-211. https://doi.org/10.3171/2015.1.JNS142661

10. Schnurman Z, Kondziolka D (2016) Evaluating innovation. Part 2: development in neurosurgery. J Neurosurg 124:212-223. https:// doi.org/10.3171/2015.1.JNS142664

11. OCEBM Levels of Evidence Working Group. "The Oxford Levels of Evidence 2". Oxford Centre for Evidence-Based Medicine

12. Dellaretti M, Reyns N, Touzet G, Dubois F, Gusmao S, Pereira JLB, Blond S (2012) Diffuse brainstem glioma: prognostic factors. J Neurosurg 117:810-814. https://doi.org/10.3171/2012.7. JNS111992

13. De Benedictis A, Trezza A, Carai A, Genovese E, Procaccini E, Messina R, Randi F, Cossu S, Esposito G, Palma P, Amante P, Rizzi M, Marras CE (2017) Robot-assisted procedures in pediatric neurosurgery. Neurosurg Focus 42:E7. https://doi.org/10.3171/2017.2. FOCUS16579

14. Carai A, Mastronuzzi A, De Benedictis A, Messina R, Cacchione A, Miele E, Randi F, Esposito G, Trezza A, Colafati GS, Savioli A, Locatelli F, Marras CE (2017) Robot-assisted stereotactic biopsy of diffuse intrinsic pontine glioma: a single-center experience. World Neurosurg 101:584-588. https://doi.org/10.1016/j.wneu.2017.02. 088

15. Coca HA, Cebula H, Benmekhbi M, Chenard MP, Entz-Werle N, Proust $F$ (2016) Diffuse intrinsic pontine gliomas in children: interest of robotic frameless assisted biopsy. A technical note. Neurochirurgie 62:327-331. https://doi.org/10.1016/j.neuchi. 2016.07.005

16. Lefranc M, Capel C, Pruvot-Occean A-S, Fichten A, Desenclos C, Toussaint P, Le Gars D, Peltier J (2015) Frameless robotic stereotactic biopsies: a consecutive series of 100 cases. J Neurosurg 122: 342-352. https://doi.org/10.3171/2014.9.JNS14107.Disclosure

17. Miller BA, Salehi A, Limbrick DDJ, Smyth MD (2017) Applications of a robotic stereotactic arm for pediatric epilepsy and neurooncology surgery. J Neurosurg Pediatr 20:364-370. https://doi.org/10.3171/2017.5.PEDS1782

18. Quick-Weller J, Tritt S, Behmanesh B, Mittelbronn M, Spyrantis A, Dinc N, Weise L, Seifert V, Marquardt G, Freiman TM (2017) Biopsies of pediatric brainstem lesions display low morbidity but strong impact on further treatment decisions. J Clin Neurosci 44: 254-259. https://doi.org/10.1016/j.jocn.2017.06.028

19. Haegelen C, Touzet G, Reyns N, Maurage C-A, Ayachi M, Blond S (2010) Stereotactic robot-guided biopsies of brain stem lesions: experience with 15 cases. Neurochirurgie 56:363-367. https://doi. org/10.1016/j.neuchi.2010.05.006

20. Grimm F, Naros G, Gutenberg A, Keric N, Giese A, Gharabaghi A (2015) Blurring the boundaries between frame-based and frameless stereotaxy: feasibility study for brain biopsies performed with the use of a head-mounted robot. J Neurosurg 123:737-742. https://doi. org/10.3171/2014.12.JNS141781

21. Glauser D, Fankhauser H, Epitaux M, Hefti JL, Jaccottet A (1995) Neurosurgical robot Minerva: first results and current developments. J Image Guid Surg 1:266-272. https://doi.org/10.1002/ (SICI) 1522-712X(1995)1:5<266::AID-IGS2>3.0.CO;2-8

22. Willems PWA, Noordmans HJ, Ramos LMP, Taphoorn MJB, Berkelbach van der Sprenkel JW, Viergever MA, Tulleken CAF (2003) Clinical evaluation of stereotactic brain biopsies with an MKM-mounted instrument holder. Acta Neurochir 145:889-897; discussion 897. https://doi.org/10.1007/s00701-003-0112-4

23. Bekelis K, Radwan TA, Desai A, Roberts DW (2012) Frameless robotically targeted stereotactic brain biopsy: feasibility, diagnostic yield, and safety. J Neurosurg 116:1002-1006. https://doi.org/10. 3171/2012.1.JNS111746

24. Minchev G, Kronreif G, Martínez-Moreno M, Dorfer C, Micko A, Mert A, Kiesel B, Widhalm G, Knosp E, Wolfsberger S (2016) A novel miniature robotic guidance device for stereotactic neurosurgical interventions: preliminary experience with the iSYS1 robot. J Neurosurg 126:1-12. https://doi.org/10.3171/2016.1.JNS152005.

25. Dlaka D, Švaco M, Chudy D, Jerbić B, Šekoranja B, Šuligoj F, Vidaković J, Almahariq F, Romić D, Svaco M, Chudy D, Jerbic B, Sekoranja B, Suligoj F, Vidakovic J, Almahariq F, Romic D (2017) Brain biopsy performed with the RONNA G3 system: a case study on using a novel robotic navigation device for stereotactic neurosurgery. Int J Med Robot Comput Assist Surg e1884. https:// doi.org/10.1002/rcs. 1884

26. Nathoo N, Cavusoglu MC, Vogelbaum MA, Barnett GH (2005) In touch with robotics: neurosurgery for the future. Neurosurgery 56 : 421-433

27. Fomenko A, Serletis D (2017) Robotic stereotaxy in cranial neurosurgery: a qualitative systematic review. Neurosurgery. https://doi. org/10.1093/neuros/nyx576

28. Ughratdar I, Samuel M, Ashkan K (2015) Technological advances in deep brain stimulation. J Parkinsons Dis 5:483-496. https://doi. org/10.3233/JPD-150579

29. Marcus HJ, Payne CJ, Hughes-Hallett A, Marcus AP, Yang G-Z Darzi A, Nandi D (2016) Regulatory approval of new medical 
devices: cross sectional study. BMJ 353. https://doi.org/10.1136/ bmj.i2587

30. Gupta P, Schomburg J, Krishna S, Adejoro O, Wang Q, Marsh B, Nguyen A, Genere JR, Self P, Lund E, Konety BR (2017) Development of a classification scheme for examining adverse events associated with medical devices, specifically the DaVinci surgical system as reported in the FDA MAUDE database. J Endourol 31:27-31. https://doi.org/10.1089/end.2016.0396

31. Georgiopoulos M, Ellul J, Chroni E, Constantoyannis C (2018) Efficacy, safety, and duration of a frameless fiducial-less brain biopsy versus frame-based stereotactic biopsy: a prospective randomized study. J Neurol Surg A Cent Eur Neurosurg 79:31-38. https:// doi.org/10.1055/s-0037-1602697

32. Khatab S, Spliet W, Woerdeman PA (2014) Frameless imageguided stereotactic brain biopsies: emphasis on diagnostic yield. Acta Neurochir 156:1441-1450. https://doi.org/10.1007/s00701014-2145-2

33. Frati A, Pichierri A, Bastianello S, Raco A, Santoro A, Esposito V, Giangaspero F, Salvati M (2011) Frameless stereotactic cerebral biopsy: our experience in 296 cases. Stereotact Funct Neurosurg 89:234-245. https://doi.org/10.1159/000325704

34. Harrisson SE, Shooman D, Grundy PL (2012) A prospective study of the safety and efficacy of frameless, pinless electromagnetic image-guided biopsy of cerebral lesions. Neurosurgery 70:29-33; discussion 33. https://doi.org/10.1227/NEU.0b013e31822d75af

35. Bradac O, Steklacova A, Nebrenska K, Vrana J, de Lacy P, Benes V (2017) Accuracy of VarioGuide frameless stereotactic system against frame-based stereotaxy: prospective, randomized, singlecenter study. World Neurosurg 104:831-840. https://doi.org/10. 1016/j.wneu.2017.04.104

36. Kulkarni AV, Guha A, Lozano A, Bernstein M (1998) Incidence of silent hemorrhage and delayed deterioration after stereotactic brain biopsy. J Neurosurg 89:31-35. https://doi.org/10.3171/jns.1998.89. 1.0031

37. Rossetti G, Milli L, Giannotti F, Pedreschi D (2017) Forecasting success via early adoptions analysis: a data-driven study. PLoS One 12:e0189096. https://doi.org/10.1371/journal.pone.0189096

38. Cardinale F, Rizzi M, d'Orio P, Casaceli G, Arnulfo G, Narizzano M, Scorza D, De Momi E, Nichelatti M, Redaelli D, Sberna M, Moscato A, Castana L (2017) A new tool for touch-free patient registration for robot-assisted intracranial surgery: application accuracy from a phantom study and a retrospective surgical series. Neurosurg Focus 42:E8. https://doi.org/10.3171/2017.2. FOCUS16539

39. Vakharia VN, Sparks R, Rodionov R, Vos S, Dorfer C, Miller J, Nilsson D, Tisdall M, Wolfsberger S, McEvoy A, Miserocchi A, Winston G, O'Keeffe A, Ourselin S, Duncan J (2017) Computer assisted planning for the insertion of stereoelectroencephalography electrodes for the investigation of drug resistant focal epilepsy: an external validation study. J Neurosurg JNS17-1826

40. Beriault S, Subaie FA, Collins DL, Sadikot AF, Pike GB (2012) A multi-modal approach to computer-assisted deep brain stimulation trajectory planning. Int J Comput Assist Radiol Surg 7:687-704. https://doi.org/10.1007/s11548-012-0768-4 